\section{D) Check for updates}

Cite this: Food Funct., 2021, 12, 3120

\title{
The protective role of Zingerone in a murine asthma model via activation of the AMPK/Nrf2/ HO-1 pathway
}

\author{
Yingjie Zhu, $\dot{\dagger}^{\mathrm{a}}$ Chunyan Wang, $\dot{\dagger}^{\mathrm{b}}$ Jingjing Luo, ${ }^{a}$ Shucheng Hua, ${ }^{\mathrm{a}}$ Dan $\mathrm{Li}{ }^{\mathrm{a}}$ \\ Liping Peng, ${ }^{\text {a }}$ Hongmei Liu*a and Lei Song (D) *a
}

\begin{abstract}
Asthma is one of the most common illnesses associated with chronic airway inflammation; however, there are currently no effective therapies apart from glucocorticoids. Zingerone (ZIN), an active compound isolated from ginger, has been reported to have a broad spectrum of pharmacological properties. In this study, Zingerone was administrated to $\mathrm{H}_{2} \mathrm{O}_{2}$-stimulated mouse airway epithelial cell line MLE12 cells and asthmatic mice. The concentration of cytokines was evaluated using enzyme-linked immunosorbent assay (ELISA). Hematoxylin-eosin (HE), Periodic Acid-Schiff (PAS) and Masson staining were used for histological analyses. Protein levels in cells or lung tissues were determined using western blot, immunohistochemistry staining. The results showed that treatment with Zingerone dramatically inhibited oxidative stress and the inflammatory response in MLE12 cells stimulated with $\mathrm{H}_{2} \mathrm{O}_{2}$ and asthmatic mice. Furthermore, Zingerone treatment could decrease the expression of phosphorylated $(p)-I_{\kappa} B \alpha$ and $p 65$ (nuclear) and increase the expression of phosphorylation of AMP-activated protein kinase ( $p$-AMPK), nuclear factor erythroid-2-related factor 2 (Nrf2), and hemeoxygenase-1 ( $\mathrm{HO}-1)$ to alleviate oxidative damage and inflammation both in vivo and in vitro. In addition, Zingerone treatment reduced the exudation and infiltration of inflammatory cells and suppressed goblet cell hyperplasia in a murine asthma model. Treatment with Zingerone also decreased the level of interleukin (IL)-4, IL-5, IL-13, and increased the level of interferon gamma (IFN- $\gamma$ ) in the BALF and attenuated airway hyperresponsiveness (AHR). However, inhibition of AMPK or Nrf2 suppressed the cellular protective, antioxidative, and anti-inflammatory properties of Zingerone. Taken together, these results demonstrate that Zingerone possesses the potential to relieve asthma via upregulating the AMPK/Nrf2/HO-1 signaling pathway.
\end{abstract}

Received 17th June 2020,

Accepted 6th November 2020

DOI: $10.1039 / \mathrm{dOfo} 01583 \mathrm{~K}$

rsc.li/food-function airway remodeling. ${ }^{3}$ Moreover, most asthmatics exhibit characteristic type 2 inflammation. ${ }^{4,5}$

Oxidative stress (OS), a condition known to result in biological damage, refers to the imbalance between oxidation and antioxidation in the body, promoting oxidation. Oxidative stress leads to an inflammatory infiltration of neutrophils, increased protease secretion, and production of a large number of oxidative intermediates. Under normal physiological conditions, the intracellular levels of reactive oxygen species (ROS) and reactive nitrogen species (RNS) are maintained at low concentrations. ${ }^{6}$ In addition, allergic asthma is often accompanied by increased ROS production and decreased antioxidant system capability, resulting in oxidative stress in the airway. ${ }^{7}$

A variety of signaling pathways are known to be associated with the pathophysiology of asthma. Nrf2, an important redoxsensitive transcription factor, has been reported to maintain cellular redox homeostasis through regulating downstream antioxidants such as $\mathrm{HO}-1, \mathrm{NAD}(\mathrm{P}) \mathrm{H}$ dehydrogenase quinone 1 (NQO1), and superoxide dismutase (SOD). ${ }^{8,9}$ As a rate-limiting 
enzyme in heme degradation, HO-1 regulates redox reactions and possesses a cytoprotective role against oxidative stress induced cell injury. Recent reports indicated that the expression of HO-1 was induced in the airways of asthmatic patients. ${ }^{10}$ Induction of HO-1 expression reduced ROS production in the airway and alleviated IL-13-induced goblet cell hyperplasia, thus protects against asthma. ${ }^{11}$ Hence, targeting Nrf2/HO-1 system may be an effective strategy for asthma prevention. AMPK is an AMP-dependent protein kinase that functions as a key molecule in the regulation of bioenergy metabolism. ${ }^{12}$ The activation of AMPK is involved in a number of signaling pathways. Recent studies indicated that AMPK activation could enhance the nuclear translocation of Nrf2, thereby enhancing HO-1 levels to relieve acute or chronic airway inflammatory diseases. ${ }^{13}$

It is currently recognized that glucocorticoids represent the most effective treatment for asthma; however, oral steroids have significant adverse effects, including glucose intolerance, as well as salt and water retention. ${ }^{14}$ Recently, small molecule compounds of traditional Chinese medicine have gained increased attention due to their unique medicinal value and few side effects. Zingerone extracted from ginger exhibits a broad spectrum of pharmacological properties. Previous research has shown that it has significant anti-oxidative, lipid metabolism, anti-pathogenic microorganism, sedative, analgesic, and antipyretic effects, which has good application prospects for cardiovascular protection and preventing liver damage. ${ }^{15-17}$ However, the mechanism by which Zingerone relieves asthma-induced airway inflammation remains unknown. These findings have prompted us to hypothesize that Zingerone may be a good candidate drug for the prevention and treatment of asthma. To address this feasibility, we aimed to investigate the protective mechanism of Zingerone on airway inflammation in a murine model of asthma.

\section{Materials and methods}

\subsection{Cell culture}

The mouse lung epithelial cell line, MLE-12 cells, were purchased from the China Cell Collection Center (Beijing, China), grown in a $5 \% \mathrm{CO}_{2}$ incubator at $37{ }^{\circ} \mathrm{C}$ with Dulbecco's Modified Eagle Medium (Gibco, Carlsbad, CA, USA) containing $10 \%$ fetal bovine serum (Gibco), $100 \mathrm{U} \mathrm{mL}^{-1}$ penicillin, and $100 \mu \mathrm{g} \mathrm{mL}{ }^{-1}$ streptomycin.

\subsection{Cell viability}

A CCK-8 assay was used to determine the level of cell viability according with the manufacturer's instructions. MLE-12 cells were seeded into 96-well plates at a density of 3000 cells per well and cultured overnight. After treatment with Zingerone and exposure to $\mathrm{H}_{2} \mathrm{O}_{2}, 10 \mu \mathrm{L}$ of the CCK-8 solution was added to each well. The absorbance at $450 \mathrm{~nm}$ was determined using a microplate reader (BioTek, Winooski, VT, USA).

For an AMPK inhibition in vitro, an AMPK inhibitor (compound C) was added to the culture medium at a final concentration of $10 \mathrm{mM}$. For Nrf2 knockdown, MLE12 cells were transfected with $50 \mathrm{nM}$ Nrf2 siRNA or scramble RNA using Lipofectamine 3000 (Thermo Fisher Scientific, Waltham, MA, USA).

\subsection{Detection of the level of reactive oxygen species (ROS)}

The level of cellular ROS was evaluated using a DCFH-DA kit (Invitrogen, Carlsbad, CA, USA). A density of $2 \times 10^{5}$ MLE12 cells were seeded into six-well plates. A final concentration of $10 \mathrm{nM}$ DCFH-DA was added to the cells for $40 \mathrm{~min}$ in an incubator containing $5 \% \mathrm{CO}_{2}$ and $90 \%$ humidity. The positively-stained cells (green fluorescence) were observed and photographed using a fluorescence microscope (Olympus, Tokyo, Japan).

\subsection{Detection of the mitochondrial membrane potential (MMP)}

The MMP was detected by a JC-1 kit (Invitrogen, Carlsbad, CA, USA). It is a fluorescent probe that can rapidly and sensitively detect cells, tissues, or purified mitochondrial membrane potential changes, and can be used for the early detection of apoptosis. A density of $2 \times 10^{5}$ MLE12 cells were seeded into six-well plates. A volume of $1 \mathrm{~mL}$ of JC-1 staining solution was added to each well, and incubated for $20 \mathrm{~min}$ in a cell culture incubator. After an incubation at $37{ }^{\circ} \mathrm{C}$, the supernatant was aspirated and washed twice with JC-1 $1 \times$ staining buffer. Next, $2 \mathrm{~mL}$ of cell culture medium was added to each well. CCCP $(10 \mu \mathrm{M})$-treated cells were used as a positive control group. The cells were observed under a fluorescence microscope.

\subsection{Superoxide dismutase (SOD), glutathione (GSH), malondialdehyde (MDA) and catalase (CAT) assays}

For the in vivo experiments, lung samples from each group of mice were collected and homogenized. The level of SOD, GSH, MDA and CAT activity in the lung homogenates were detected using commercial kits purchased from the Beyotime Institute of Biotechnology (Shanghai, China) according to the manufacturer's instructions. For the in vitro experiments, MLE12 cells were cultured in 6 -well plates $\left(2 \times 10^{5}\right.$ cells per well $)$. After Zingerone and $\mathrm{H}_{2} \mathrm{O}_{2}$ exposure, the cells were collected, washed with PBS, and centrifuged for $5 \mathrm{~min}\left(12000 \mathrm{~g}\right.$ at $\left.4{ }^{\circ} \mathrm{C}\right)$. The sediment was lysed with precipitation lysis buffer on ice (30 min), and the supernatant was collected to measure the SOD activity and MDA levels.

\subsection{Lactate dehydrogenase (LDH) activity}

The degree of $\mathrm{H}_{2} \mathrm{O}_{2}$-induced cellular damage was evaluated using an LDH Assay Kit (Beyotime, China). Under lactate dehydrogenase activity, NAD+ is reduced to NADH. NADH and INT (2-p-iodophenyl-3-nitrophenyltetrazolium chloride) are catalyzed by lipoamide to form NAD+ and strong chromophore. An absorption peak is generated at a wavelength of $490 \mathrm{~nm}$, whereby the activity of lactate dehydrogenase can be quantified by colorimetry. The absorbance is linearly positively correlated with the level of lactate dehydrogenase activity. MLE12 cells were seeded into 96-well cell culture plates. After stimulation with Zingerone and $\mathrm{H}_{2} \mathrm{O}_{2}$, the cell culture plate was centrifuged at $400 \mathrm{~g}$ for $5 \mathrm{~min}$ in a multi-well plate centrifuge. After discarding the supernatant, $150 \mu \mathrm{L}$ of the $\mathrm{LDH}$ release reagent was added (1 volume of $\mathrm{LDH}$ release reagent was 
added to 10 volumes of PBS) and incubated for $1 \mathrm{~h}$. The cell culture plates were then centrifuged for 5 min using a multiwell plate centrifuge at $400 \mathrm{~g}$. Next, $120 \mu \mathrm{L}$ of the supernatant from each well was added to the corresponding wells of a new 96-well plate, and the sample was measured.

\subsection{Real-time quantitative polymerase chain reaction (qPCR)}

The total RNA was extracted using TRIzol reagent (Invitrogen, CA, USA). A Superscript III Reverse Transcriptase kit (Invitrogen) was utilized to synthesize cDNA. A solution of $2.5 \mu \mathrm{L}$ cDNA and $1 \mu \mathrm{L}$ of specific primers was thoroughly mixed with TransStartTM SYBR Green qPCR Supermix (Transgene, Beijing, China). qPCR was performed using an ABI 7500 PCR system (ABI, USA). GAPDH mRNA served as an internal reference. The PCR products were quantitatively analyzed.

\subsection{Nrf2 short hairpin RNA (shRNA) lentiviral transduction particle production}

A lentiviral shRNA vector targeting Nrf2 was generated by inserting stranded oligonucleotides (shRNA1, forward sequence 5'-CCGGGCCTTACTCTCCCAGT GAATACTCGAGTATT CACTGGGAGAGTAAGGCTTTTTG-3'; shRNA2, forward sequence 5'-CCGGCTTGAAGTCTTCAGCATGTTACTCGAGTA; ACATGCTGAAGACTTCAAGTTTTTG-3'; shRNA3, forward sequence 5'-CCGGCCAGCAGGACATGGATTTGATCTCGAGA; TCAAATCCATGTCCTGCTGGTTTTT-3') into a plKO.1 vector (Sigma). A shRNA vector was co-transfected into HEK-293T cells with pGag/Pol, pRev, and pVSV-G using lip3000. At $16 \mathrm{~h}$ post-transfection, the media was gently removed from the transfected cells and replaced with pre-warmed complete media. The cells were incubated for an additional $24 \mathrm{~h}$ and the virus-containing supernatant was collected. The viruses were concentrated by ultra-centrifugation and the titer was determined by qPCR.

\subsection{Animals and treatment}

BALB/c mice (6-8 weeks old) were purchased from the Center of Experimental Animals of Jilin University. The mice were housed in cages in which the temperature was maintained at $24^{\circ} \mathrm{C} \pm 2{ }^{\circ} \mathrm{C}$. All mouse care and experimental procedures were performed under specific pathogen-free (SPF) conditions in accordance with the established institutional guidance and approval from the Research Animal Care Committee in Jilin University for Animal Experimentation.

To establish a model of asthma, all of the mice, except the control group, were sensitized by an intraperitoneal injection of $20 \mu \mathrm{g}$ ovalbumin (OVA, Sigma-Aldrich, China), and $1 \mathrm{mg}$ aluminum hydroxide adjuvant (Imject® Alum; Pierce, USA) diluted in $200 \mu \mathrm{L}$ phosphate-buffered saline (PBS) on days 1, 7, and 14. The Control group received an equivalent amount of PBS. The sensitized mice were challenged by OVA (1\% OVA in PBS) by intranasal inhalations for $30 \mathrm{~min}$ each day from days 21 to 23. For treatment, mice were subjected to Zingerone administration from days 17 to 23 , at $1 \mathrm{~h}$ before challenge.

Zingerone was prepared and administrated through intraperitoneal injection (i.p.) described as before. ${ }^{18,19}$ A total of 48 mice were randomly divided into eight groups (six mice per group): Control group, OVA-administrated model group (OVA), Zingerone $25 \mathrm{mg}$ per $\mathrm{kg}$ body weight (BW)-treated group (OVA + ZIN25), Zingerone $50 \mathrm{mg}$ per $\mathrm{kg}$ BW-treated group (OVA + ZIN50), Zingerone $50 \mathrm{mg}$ per $\mathrm{kg}$ BW-treated + compound C-treated group (compound C), Zingerone $50 \mathrm{mg}$ per $\mathrm{kg} \mathrm{BW}$ treated + DMSO-treated group (DMSO), Zingerone $50 \mathrm{mg}$ per $\mathrm{kg}$ BW-treated + Nrf2 shRNAs lentiviral vector-treated group (Lenti-si-Nrf2) and Zingerone $50 \mathrm{mg}$ per kg BW-treated + negative control shRNA-treated group (MOCK).

To interfere with Nrf2 expression in the lung, Nrf2 shRNA lentiviral vectors $\left(2.2 \times 10^{6}\right.$ IFU) were intratracheally (IT)-delivered into the animals two days before the first challenge with OVA as previously reported. ${ }^{20} \mathrm{~A}$ mock virus (negative control shRNA) was used as the control.

To inhibit the AMPK pathway in vivo, compound C $(20 \mathrm{mg}$ $\mathrm{kg}^{-1}$ ) was injected into the abdominal cavity daily for two days before the first OVA challenge as previously reported. ${ }^{21}$

\subsection{Bronchoalveolar lavage fluid}

Mice were euthanized at $24 \mathrm{~h}$ after the last challenge, the trachea was isolated by blunt dissection, and a small-caliber tube was inserted into the airway and fixed. Then, $1 \mathrm{~mL}$ of phosphate-buffered saline was instilled and gently aspirated. The alveolar lavage fluid supernatant was used to measure the level of cytokines. Cold PBS was used to resuspend the cell pellets. Differential cell counts were performed after cytocentrifugation.

\subsection{Diff-quick staining}

The BALF samples were centrifuged and the cell pellets were resuspended in cold PBS. The eosinophils, neutrophils, macrophages, and lymphocytes in the BALF were stained with Diffquick staining (Baxter, Switzerland) in accordance with the manufacturer's protocols.

\subsection{Measurement of AHR}

AHR was detected using non-invasive whole-body plethysmography (Model PLY 3211; Buxco, Sharon, CT, USA) 24 h after the final OVA treatment. A whole-body plethysmography tracer was divided into a main chamber and a reference chamber. Conscious and self-breathing mice were placed in the main body to inhale different concentrations of methacholine. Penh (enhanced pause) was used to measure AHR.

\subsection{Lung histology}

The left lungs of the mice were completely removed and fixed with $4 \%$ formaldehyde. The tissues were embedded in paraffin after fixing for $24 \mathrm{~h}$. The $4 \mu \mathrm{m}$ lung sections were prepared for $\mathrm{HE}$, PAS, and Masson staining for examination under a light microscope.

\subsection{Immunohistochemistry}

Lung sections were kept in an oven at $60^{\circ} \mathrm{C}$ for $2 \mathrm{~h}$. The slides were deparaffinized and dehydrated through xylene and graded concentrations of alcohol, then placed in a retrieval solution and incubated in a microwave at high power for $15 \mathrm{~min}$. The slides were then cooled and washed with wash 
buffer and incubated sequentially with Nrf2, HO-1 and p65 (Proteintech, China), followed by a biotin-labeled secondary antibody (Proteintech, China). Finally, the sections were stained using the diaminobenzidine (DAB) method, counterstained with hematoxylin, cleared in xylene, and fixed.

\subsection{Enzyme-linked immunosorbent assay (ELISA)}

In the in vivo experiments, the level of cytokines in the supernatants of the alveolar lavage fluids were evaluated using an ELISA. Briefly, the alveolar lavage fluid was centrifuged at $4{ }^{\circ} \mathrm{C}$, $270 \mathrm{~g}$ for $5 \mathrm{~min}$, and the supernatant was stored in a $-20{ }^{\circ} \mathrm{C}$ refrigerator. The secretion of inflammatory cytokines was determined using an ELISA kit (R\&D systems) according to the manufacturer's instructions, followed by measurements on a microplate reader at $450 \mathrm{~nm}$. Similarly, in the in vitro experiments, MLE-12 cells were treated with $500 \mu \mathrm{L}$ of ice-cold PBS with protease inhibitors, and the cells were disintegrated using an ultrasonic homogenizer. The mixture was centrifuged at $12000 \mathrm{~g}$ for $20 \mathrm{~min}$. The supernatant was obtained to measure the cytokine levels.

\subsection{Western blot analysis}

The total proteins from the lung tissues or MLE12 cells were extracted using a RIPA Kit (Beyotime, Shanghai, China) according to the manufacturer's instructions. The nuclear and cytoplasmic proteins from the lung tissues or MLE12 cells were extracted using a detection kit (Beyotime, Shanghai, China) according to the manufacturer's instructions. The protein con- centrations were determined with a BCA protein assay kit to ensure that the protein loading volume was consistent between wells. A total of $40 \mu \mathrm{g}$ protein was separated by $10 \%$ sodium dodecyl-sulfate polyacrylamide gel electrophoresis and transferred onto polyvinylidene fluoride membranes. The membranes were incubated with primary antibodies. Antibodies against p-IкB $\alpha, \mathrm{I} \kappa \mathrm{B} \alpha, \mathrm{p} 65$, p-AMPK, AMPK, Nrf2, HO-1, Lamin B and GAPDH were purchased from Proteintech (China). The following day, the band was removed, and the membrane was incubated with horseradish peroxidase (HRP)labeled secondary antibodies at room temperature for $2 \mathrm{~h}$. Finally, the membranes were detected by with enhanced chemiluminescence detection reagents.

\subsection{Statistical analysis}

The data were analyzed using SPSS 22.0 software (SPSS Inc., Chicago, IL, USA). Data were expressed as the mean \pm standard deviation. The grouped data were expressed as a relative number. Group comparison was carried out using an analysis of variance and the $Q$ test. Statistical significance was defined as $p<0.05$.

\section{Results}

\subsection{Zingerone protects MLE-12 cells from oxidative stress- induced cellular injury}

Oxidative stress in the airway plays a pivotal role in pathogenesis and progression of asthma. $\mathrm{H}_{2} \mathrm{O}_{2}$ is a common oxidant for

(a)
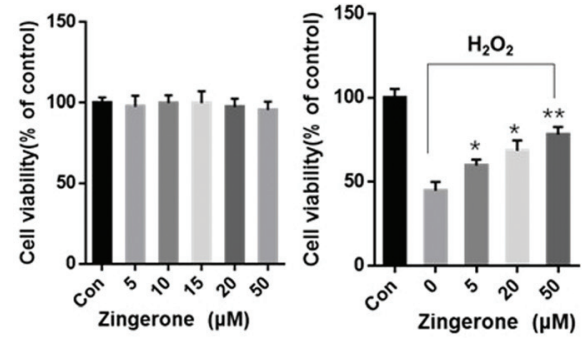

(b)
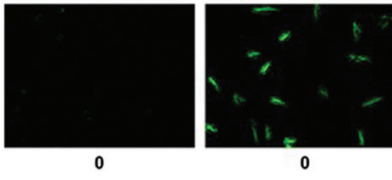

CCCP+Zingerone (
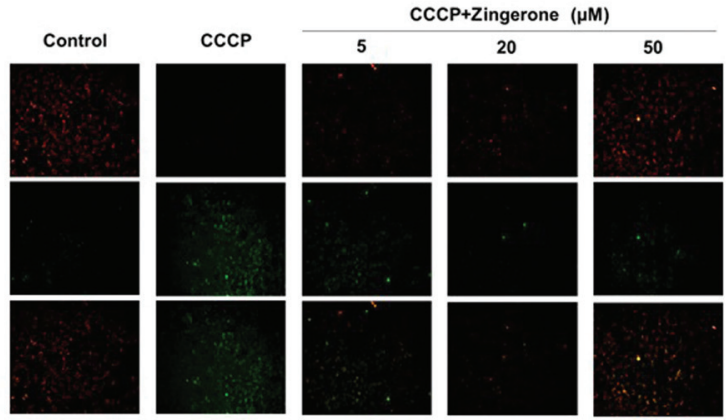

(d)

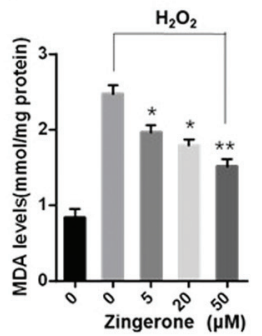

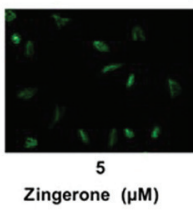
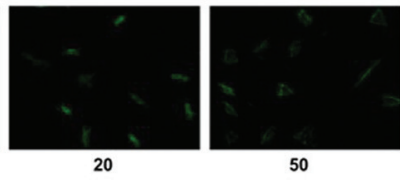

(e)
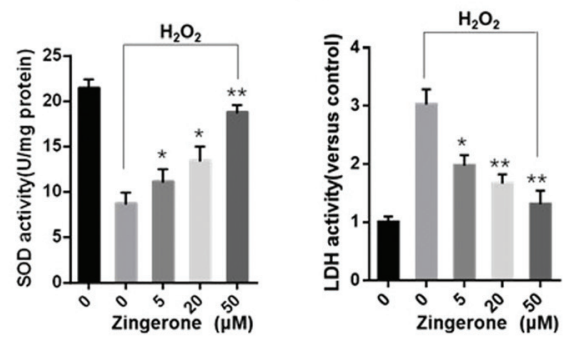

Fig. 1 Zingerone protects MLE-12 cells from oxidative stress-induced cellular injury. (a) The effects of different concentrations of ZIN (5-50 $\mu M$ ) on cell viability with or without $\mathrm{H}_{2} \mathrm{O}_{2}$ stimulation. (b) The ROS level (green fluorescence intensity) was remarkably higher in MLE12 cells subjected to $\mathrm{H}_{2} \mathrm{O}_{2}$ (2nd panel) than that in the control group (1st panel). After treatment with different concentrations of ZIN, the fluorescence intensity was lower in MLE12 cells than that in cells without treatment, in a dose-dependent manner. (c) Treatment with ZIN remarkably attenuated the decrease of MMP from ROS-induced injury. (d) ZIN treatment significantly upregulated SOD activity and downregulated the MDA level in MLE12 cells subjected to $\mathrm{H}_{2} \mathrm{O}_{2}$ in a dose-dependent manner. (e) $\mathrm{ZIN}$ clearly decreased the MLE12 cell LDH activity induced by $\mathrm{H}_{2} \mathrm{O}_{2}$. Zingerone refers to as $\mathrm{ZIN}$ for short in this and following figures. The data of each group were from three independent assays. ${ }^{*} P<0.05$ versus $0 \mu \mathrm{M} Z \mathrm{ZIN}$ with $\mathrm{H}_{2} \mathrm{O}_{2} ;{ }^{* \star} P<0.01$ versus $\mathrm{O} \mu \mathrm{M}$ ZIN with $\mathrm{H}_{2} \mathrm{O}_{2}$. 
induction of oxidative stress, ${ }^{22-24}$ thus MLE12 cells stimulated with $\mathrm{H}_{2} \mathrm{O}_{2}$ was used to explore the effects of Zingerone on ROS-induced lung epithelial cells injury. A CCK-8 kit was used to select the optimal therapeutic concentration of Zingerone on MLE12 cells. As concentration gradually increased (5-50 $\mu \mathrm{M})$, the MLE12 cell viability was not affected. A CCK-8 kit was also used to evaluate the protective effects of different concentrations of Zingerone on $\mathrm{H}_{2} \mathrm{O}_{2}$-induced cellular injury in MLE-12 cells (Fig. 1a). The anti-oxidative activity of Zingerone in MLE-12 cells stimulated with $\mathrm{H}_{2} \mathrm{O}_{2}$ was evaluated by DCFH-DA staining. Fig. $1 \mathrm{~b}$ showed that $\mathrm{H}_{2} \mathrm{O}_{2}$ could significantly increase the ROS in MLE-12 cells. However, Zingerone treatment remarkably decreased the accumulation of ROS induced by $\mathrm{H}_{2} \mathrm{O}_{2}$ in a dose-dependent manner.

Mitochondria are important organelles for promoting cell energy conversion and participating in cell apoptosis. When cells undergo apoptosis, the process is always accompanied by a decrease in MMP. As shown in Fig. 1c, the transition from red fluorescence to green fluorescence could detect a decrease in the cell membrane potential. The JC- 1 assay revealed a decrease in MMP in the cells stimulated with $\mathrm{H}_{2} \mathrm{O}_{2}$, whereas treatment with Zingerone remarkably decreased the ratio of green cells. Moreover, Zingerone significantly upregulated SOD activity, and decreased the level of MDA in the MLE12 cells subjected to $\mathrm{H}_{2} \mathrm{O}_{2}$ in a dose-dependent manner (Fig. 1d). The LDH assay was used to reveal damaged cells. The results revealed that Zingerone clearly relieved the cellular injury (Fig. 1e).

\subsection{Zingerone ameliorates oxidative stress-induced activation of NF- $\kappa B$ and inflammation in MLE12 cells}

It has been well-established that NF- $\kappa \mathrm{B}$ plays a key role in regulating the immune response to inflammation. Thus, we further determined whether the NF-кB pathway was involved in the protective effects of Zingerone. Compared to the control group, stimulation with $\mathrm{H}_{2} \mathrm{O}_{2}$ increased the expression of $\mathrm{p}-\mathrm{I} \kappa \mathrm{B} \alpha$ and p65 (nuclear). Treatment with Zingerone significantly suppressed the activation of NF- $\kappa \mathrm{B}$ in a dose-dependent manner (Fig. 2a). Furthermore, Zingerone clearly reduced the level of TNF- $\alpha$ and IL-1 $\beta$ protein in the culture medium of $\mathrm{H}_{2} \mathrm{O}_{2}$-stimulated MLE12 cells and mRNA expression induced by $\mathrm{H}_{2} \mathrm{O}_{2}$ in a dose-dependent manner (Fig. 2b and c).

\subsection{Zingerone alleviates oxidative stress in asthmatic mice} lung tissue

To evaluate the antioxidant effect of Zingerone on asthmatic mice, SOD activity, MDA and GSH as well as CAT levels were (a)
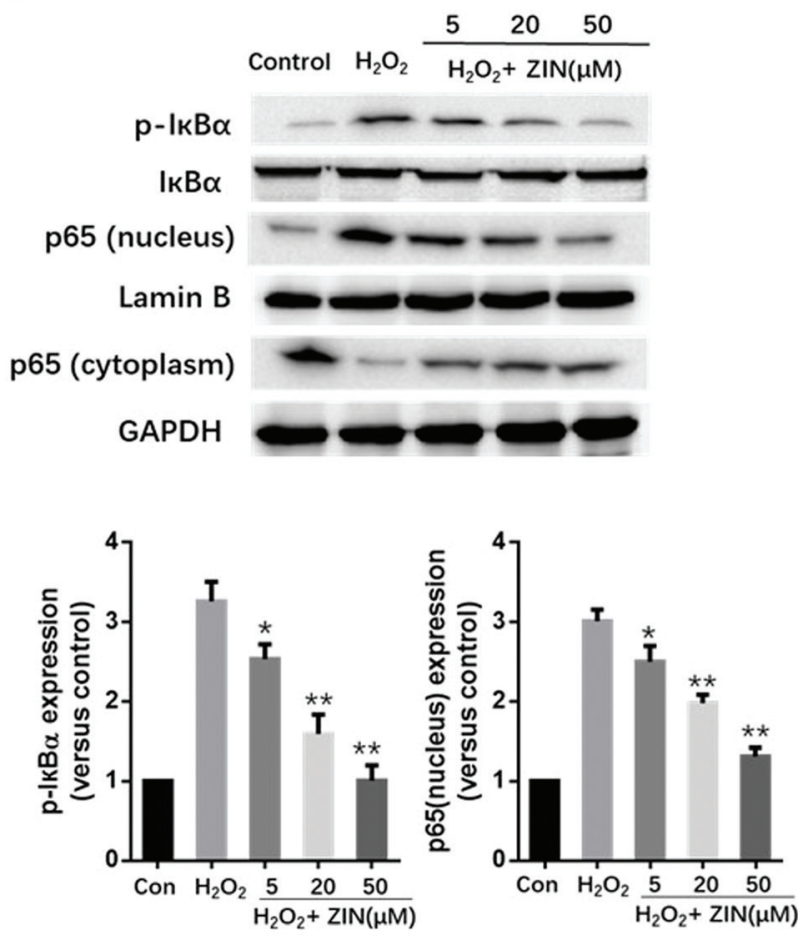

(b)

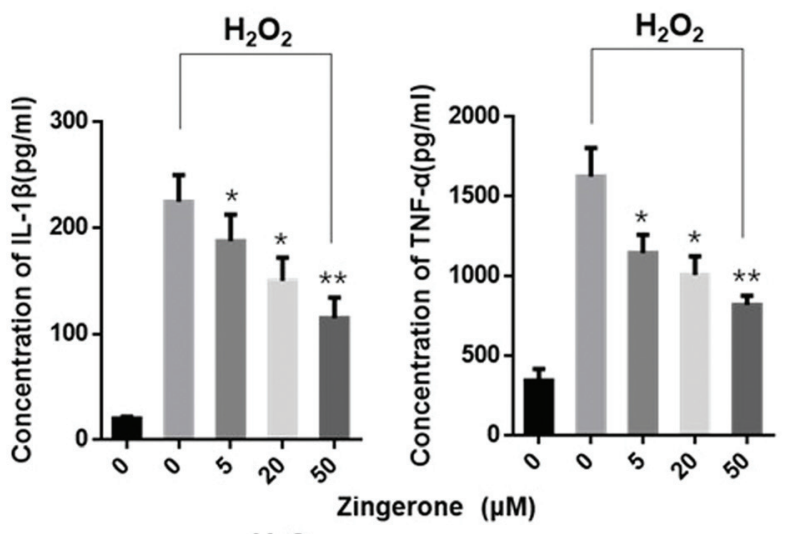

(c)

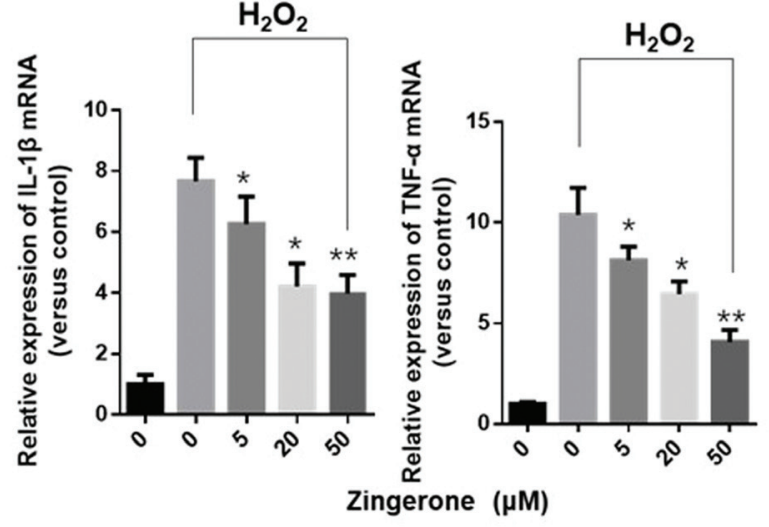

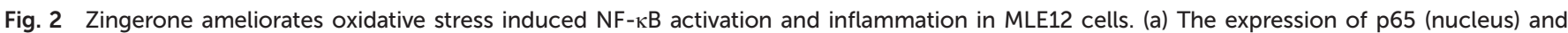

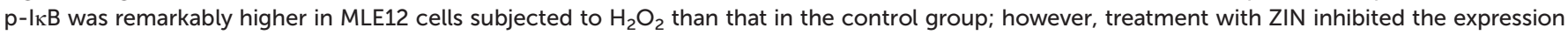

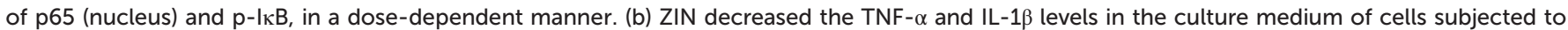

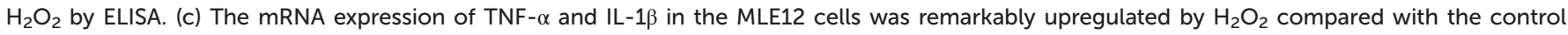

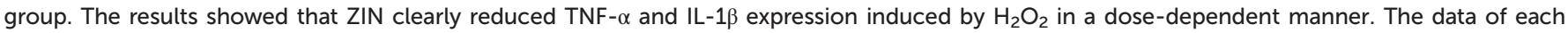
group were generated from three independent assays. ${ }^{\star} P<0.05$ versus $0 \mu \mathrm{M} Z \mathrm{IIN}$ with $\mathrm{H}_{2} \mathrm{O}_{2}$; ${ }^{* \star} P<0.01$ versus $0 \mu \mathrm{M} Z \mathrm{IN}$ with $\mathrm{H}_{2} \mathrm{O}_{2}$. 
(a)

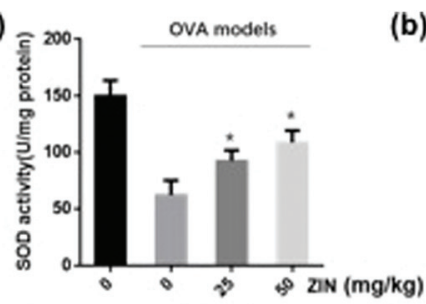

(c)

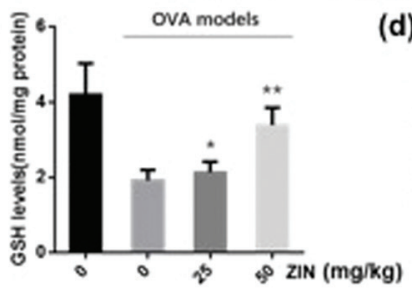

(b)

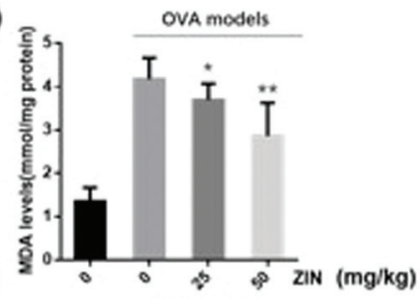

d)

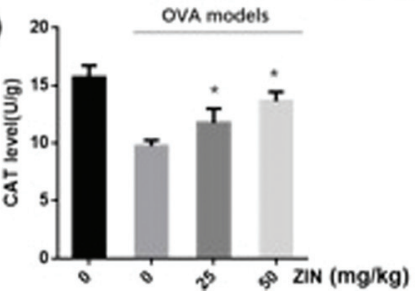

(e)
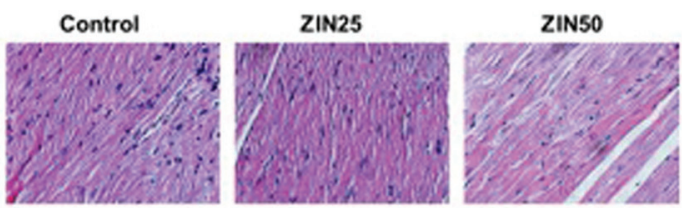

Kidney
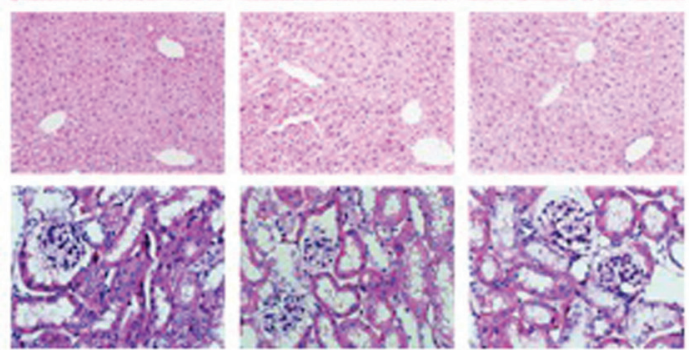

Fig. 3 Zingerone alleviates oxidative stress in the lung tissue of asthmatic mice. (a-d) After treatment with ZIN, SOD activity, MDA level, GSH level, and CAT level in the lung tissues were evaluated. (e) The HE staining of heart, liver, and kidney of asthmatic mice treated with different concentrations of ZIN. The data of each group were from three independent assays. ${ }^{*} P<0.05$ versus $0 \mathrm{mg} \mathrm{kg}^{-1} \mathrm{ZIN}$ with OVA; ${ }^{* \star} P<0.01$ versus 0 mg kg ${ }^{-1}$ ZIN with OVA.

measured in the lungs using commercial kits. As shown in Fig. 3a-d, MDA content was remarkably increased in the model (OVA without Zingerone) group, which was accompanied by a marked decrease in SOD activity, GSH, and CAT content. Treatment with different doses of Zingerone could significantly decrease the MDA levels, increase the level of GSH and CAT, and enhance SOD activity in asthmatic mice. Furthermore, we confirmed that treatment of Zingerone at a concentration of 25 or $50 \mathrm{mg} \mathrm{kg}^{-1}$ had no obvious toxicity to major organs of asthmatic mice (Fig. 3e). (a)

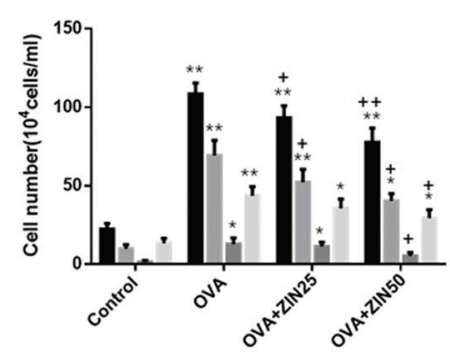

(c)
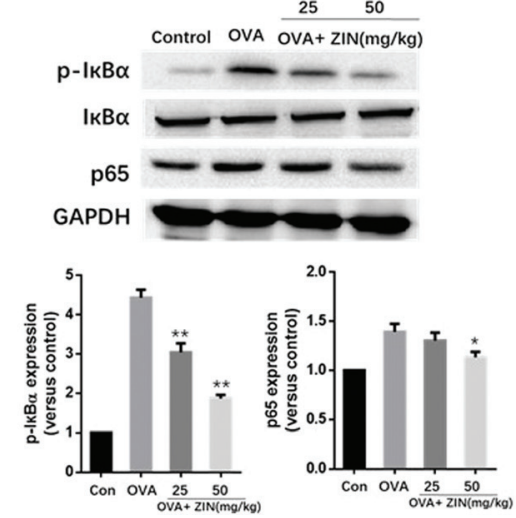

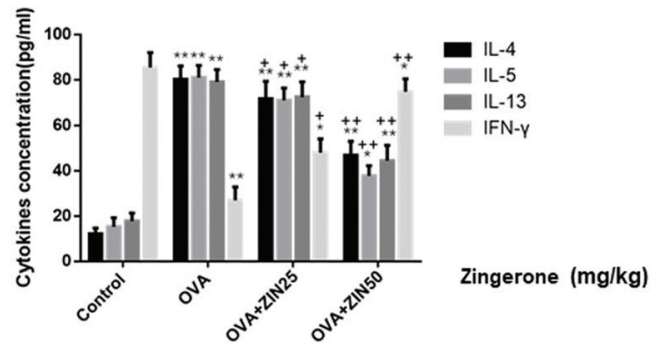

(b)

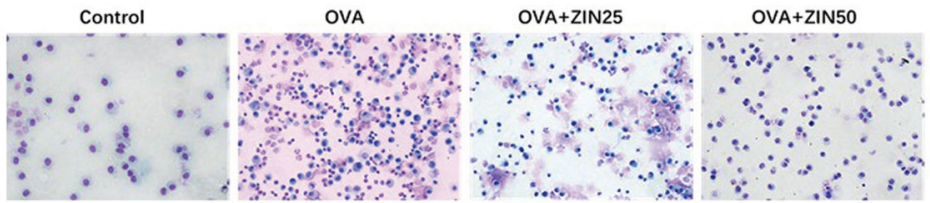

(d)
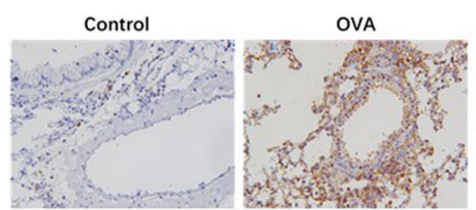

OVA+ZIN25

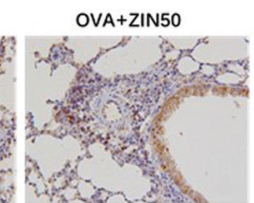

Fig. 4 Zingerone alleviated airway inflammation in asthmatic mice. (a) ZIN significantly decreased the total cell counts, as well as the neutrophil, eosinophil percentage compared to the model group. Furthermore, the IL-4, IL-5, and IL-13 levels in the BALF of the OVA group were decreased after treatment with ZIN. In contrast, the level of INF- $\gamma$ increased after treatment. ${ }^{*} P<0.05$ versus control group; ${ }^{* *} P<0.01$ versus control group. ${ }^{+} P$ $<0.05$ versus $0 \mathrm{mg} \mathrm{kg}^{-1}$ ZIN with OVA; ${ }^{++} P<0.01$ versus $0 \mathrm{mg} \mathrm{kg}^{-1}$ ZIN with OVA. (b) Representative image of the differential cells in the BALF (diffquick staining). (c) Treatment with ZIN inhibited the expression of p65 and $\mathrm{p}$-IKB in asthmatic mice lung tissue. ${ }^{*} P<0.05$ versus 0 mg kg ${ }^{-1} Z \mathrm{ZIN}$ with OVA; ${ }^{\star *} P<0.01$ versus $0 \mathrm{mg} \mathrm{kg}^{-1} \mathrm{ZIN}$ with OVA. (d) Immunohistochemical staining showed that ZIN significantly decreased the nuclear translocation of $p 65$ in the lung tissue of asthmatic mice. The data of each group were generated from three independent assays. 
(a)

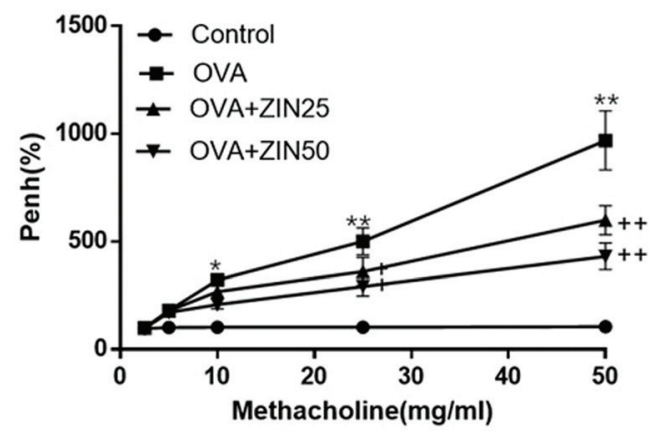

(b)

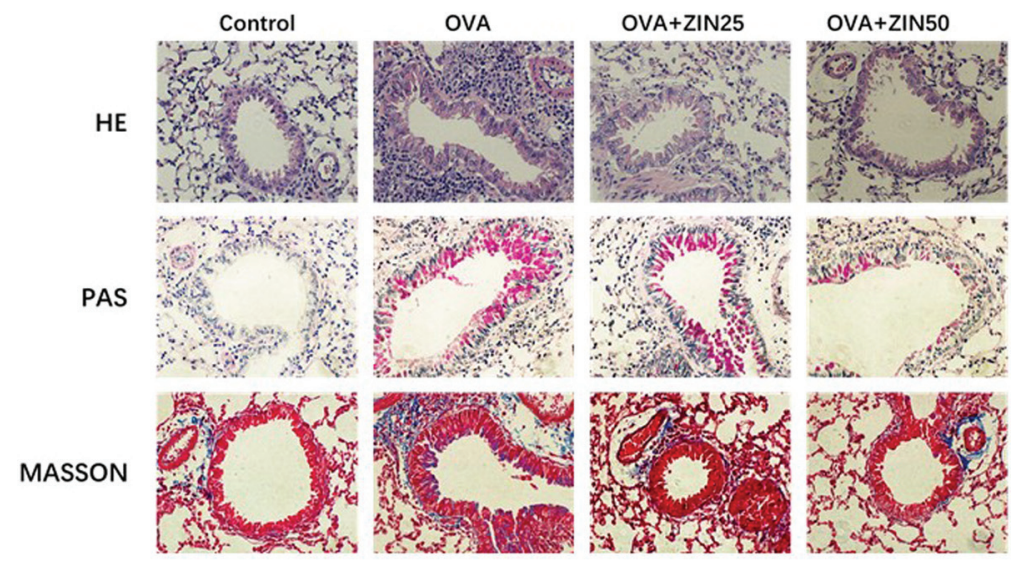

Fig. 5 Effect of Zingerone on OVA-induced AHR and histopathological changes of the lung tissue. (a) ZIN alleviated AHR in a mouse model of asthma. (b) HE, PAS, and Masson staining showed that ZIN remarkably reduced the inflammatory cells, the goblet cells in the airway epithelium, and relieved airway epithelial collagen fibrosis compared with the OVA group in a dose-dependent manner. ${ }^{*} P<0.05$ versus control group; ${ }^{* \star} P<0.01$ versus control group. ${ }^{+} P<0.05$ versus $0 \mathrm{mg} \mathrm{kg}^{-1}$ ZIN with OVA; ${ }^{++} P<0.01$ versus $0 \mathrm{mg} \mathrm{kg}^{-1}$ ZIN with OVA. The data from each group were generated from three independent assays.

3.4 Zingerone alleviates airway inflammation in asthmatic mice

To further estimate the anti-inflammatory effect of Zingerone on asthmatic mice, BALF was collected to count the number of inflammatory cells. Compared with the control group, the OVA group showed an apparent increase in the total inflammatory cells including eosinophils, neutrophils, and lymphocytes. The level of IL-4, IL-5, IL-13, and IFN- $\gamma$ in the BALF were analyzed (a)

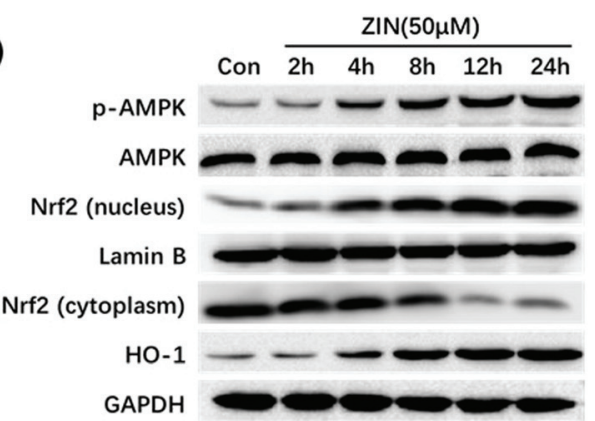

(b)

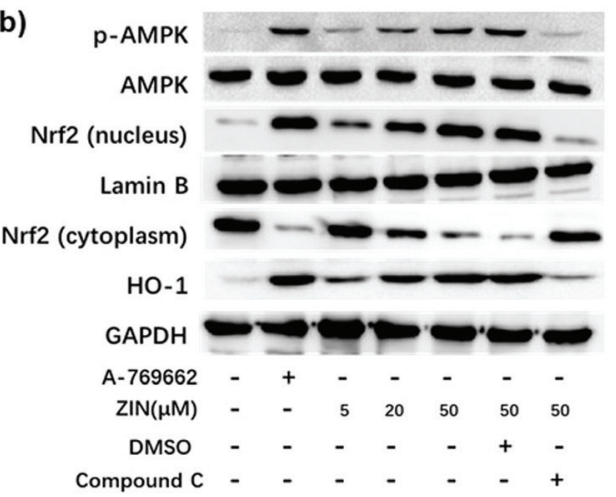

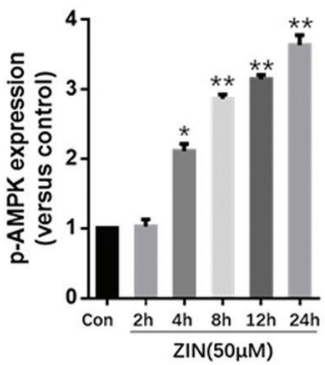
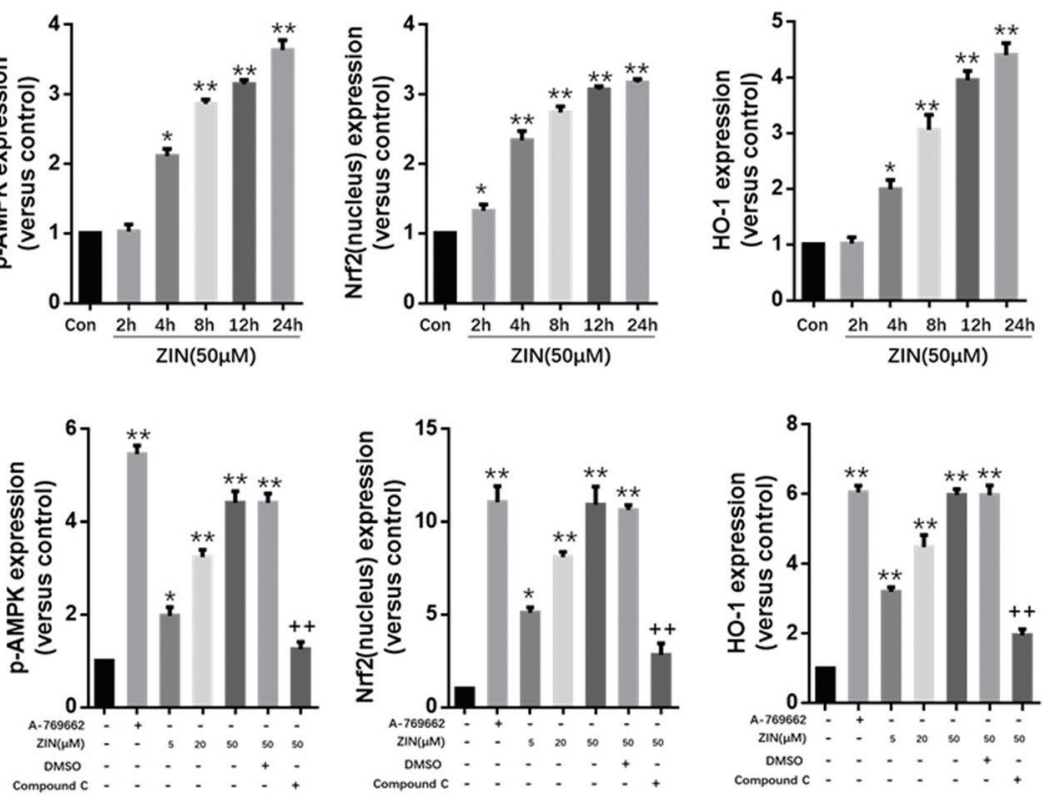

Fig. 6 Zingerone activates the AMPK/Nrf2/HO-1 pathway in MLE12 cells. (a) MLE12 cells were incubated with a ZIN solution at 50 $\mu$ M for 2, 4, 8, 12, and $24 \mathrm{~h}$. The Western results show that treatment with ZIN increased the expression of p-AMPK, Nrf2 (nucleus), and HO-1 in a time-dependent manner. ${ }^{*} P<0.05$ versus control group; ${ }^{* *} P<0.01$ versus control group. (b) MLE12 cells pretreated with A-769662 (AMPK agonist) were used as a positive control group. The Western results showed that treatment with ZIN dose-dependently increased the expression of $p$-AMPK, Nrf2 (nucleus), and HO-1. However, this effect could be blocked by compound C (AMPK inhibitor). ${ }^{\star} P<0.05$ versus blank group; ${ }^{\star \star} P<0.01$ versus blank group (A769662-ZIN-DMSO-compound C-). ${ }^{+} P<0.05$ versus positive control group or ZIN $(50 \mu \mathrm{M})$ treatment group; ${ }^{++} P<0.01$ versus positive control group or ZIN $(50 \mu \mathrm{M})$ treatment group. The data for each group were generated from three independent assays. 
using commercial kits, and the results demonstrated that the OVA+ Zingerone group showed an obvious decrease in the content of IL-4, IL-5, IL-13, and IFN- $\gamma$ in the alveolar lavage fluid supernatant in a dose-dependent manner (Fig. 4a). A representative image of the differential cells (by Diff-quick staining) is presented in Fig. $4 \mathrm{~b}$.

The effect of Zingerone on $\mathrm{p}-\mathrm{I} \kappa \mathrm{B} \alpha$ and $\mathrm{p} 65$ expression in an asthmatic mice model was further assessed. The results of a western blot assay revealed that treatment with Zingerone (50 $\mathrm{mg} \mathrm{kg}^{-1}$ ) inhibited the expression of $\mathrm{p}-\mathrm{I} \kappa \mathrm{B} \alpha$ and $\mathrm{p} 65$ compared with the OVA model group (Fig. 4c). Immunohistochemical staining showed that the OVA+ Zingerone group exhibited decreased nuclear translocation of p65 (Fig. 4d).

\subsection{Effect of Zingerone on OVA-induced AHR and histopathological changes of the lung tissue}

Mice inhaled increased doses of methacholine, and AHR was measured by increases in Penh values from baseline. The results showed that the Penh values of the OVA-challenged mice were higher than that of the control group. However, a significant reduction in the Penh value was observed in mice treated with Zingerone (Fig. 5a).

The lung tissues from each group were processed for histological evaluation. HE staining was used to observe the mor- phological changes in the lung tissue, which reflected inflammation in the bronchus. HE staining showed that the number of infiltrating inflammatory cells around the airway in the OVA group was remarkably higher than that in the control group, whereas Zingerone treatment remarkably reduced the number of inflammatory cells in a dose-dependent manner. Goblet cells are rare among respiratory epithelial cells, but rapidly increase if stimulated by allergens or inflammation. PAS staining was used to evaluate the degree of goblet cell hyperplasia. Zingerone could substantially reduce the number of goblet cells in the airway epithelium and mucus hypersecretion in a dose-dependent manner. Masson staining was used to show the degree of collagen fiber proliferation in the mouse lung tissue. Zingerone treatment relieved airway epithelial collagen fibrosis compared with the OVA group (Fig. 5b).

\subsection{Zingerone activates the AMPK/Nrf2/HO-1 pathway in MLE12 cells}

In vivo and in vitro experiments were conducted separately to demonstrate the role of AMPK/Nrf2/HO- 1 in Zingeronemediated protection against asthma. For the in vitro experiments, MLE12 cells were incubated in a Zingerone solution at $50 \mu \mathrm{M}$ for $2,4,8,12$, and $24 \mathrm{~h}$ or with different concentrations $(5,20,50 \mu \mathrm{M})$ of Zingerone for $24 \mathrm{~h}$. The levels of p-AMPK,

(a)
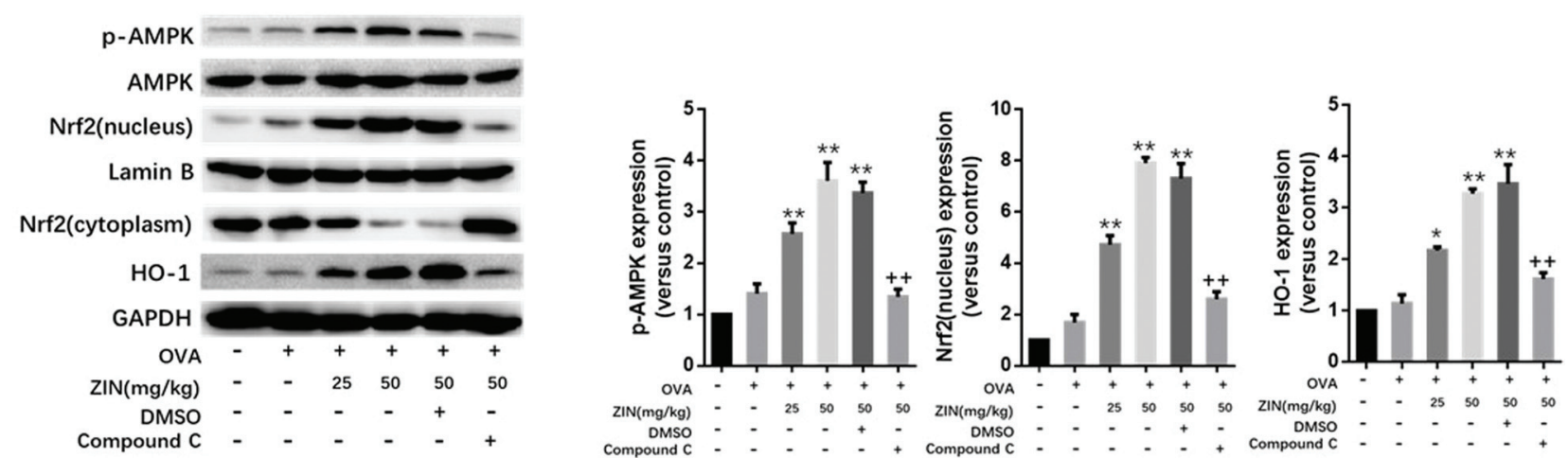

(b)
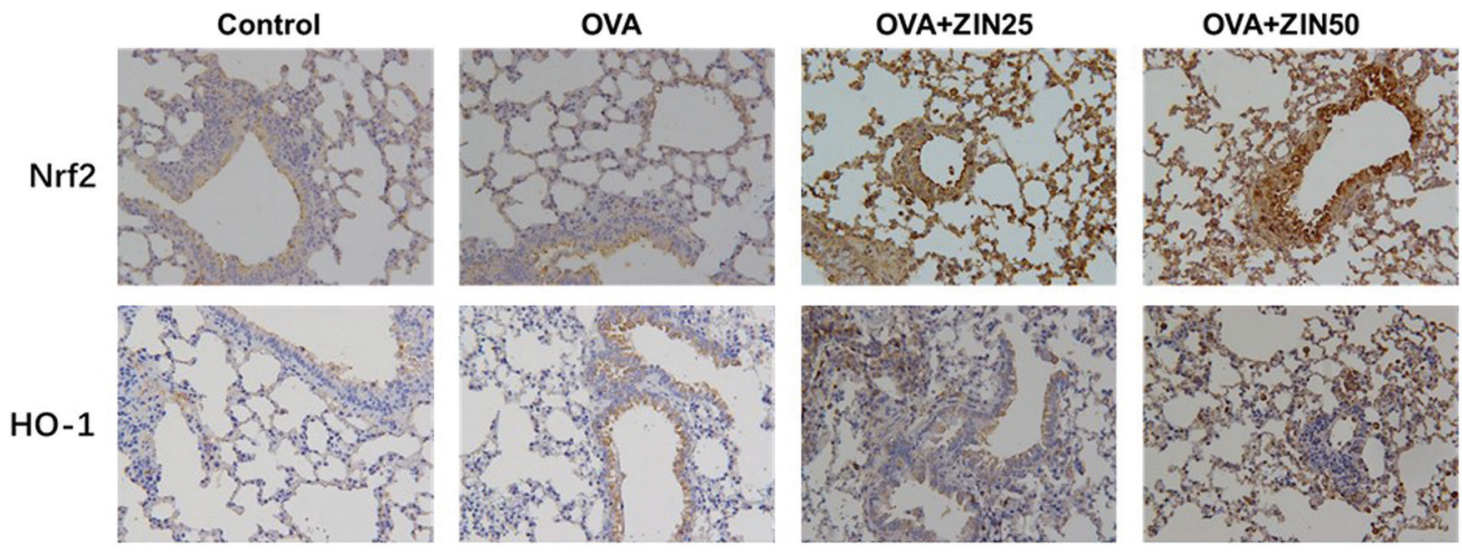

Fig. 7 Zingerone activates the AMPK/Nrf2/HO-1 pathway in asthmatic mice. (a) After treatment with different concentrations of ZIN with or without compound $\mathrm{C}$, the expression of $\mathrm{p}$-AMPK, AMPK, Nrf2, and HO-1 were analyzed by western blot. ${ }^{*} P<0.05$ versus control group; ${ }^{* *} P<0.01$ versus control group. ${ }^{+} P<0.05$ versus $50 \mathrm{mg} \mathrm{kg}^{-1} \mathrm{ZIN}$ in the OVA models; ${ }^{++} P<0.01$ versus $50 \mathrm{mg} \mathrm{kg}^{-1} \mathrm{ZIN}$ in the OVA models (DMSO-compound C-). (b) Immunohistochemical staining showed that treatment with ZIN significantly increased the nuclear translocation of Nrf2 and expression of HO-1. The data of each group were generated from three independent assays. 
AMPK, Nrf2 (nucleus and cytoplasm), and HO-1 were determined by immunoblotting. The results demonstrated that Zingerone stimulated the expression of p-AMPK, Nrf2 (nucleus), and HO-1 in MLE12 cells in a time and dose-dependent manner. A-769662, an effective, reversible AMPK activator, was used as a positive control. After the cells were pretreated with compound C (AMPK inhibitor), Zingerone-induced upregulation of p-AMPK, Nrf2, and HO-1 expression was significantly restored compared with the Zingerone treatment group (Fig. 6a and b).

\subsection{Zingerone activates the AMPK/Nrf2/HO-1 pathway in asthmatic mice}

For the in vivo experiments, as the dose of Zingerone increased, the expression of p-AMPK, Nrf2 (nucleus), and HO-1 increased 2.5-4 fold in the OVA+ Zingerone group (Fig. 7a) compared with that of the control group. However, compound C significantly reversed this effect of Zingerone.

Pathological immunohistochemistry of the lung tissue showed higher levels of Nrf-2 and HO-1 expression around the airway of the OVA+ Zingerone group compared to that of the control group. Furthermore, Zingerone treatment clearly promoted the nuclear translocation of the Nrf-2 protein (Fig. 7b).

3.8 Inhibition of AMPK/Nrf2 blocks the protective effect of Zingerone in MLE12 cells subjected to $\mathrm{H}_{2} \mathrm{O}_{2}$

MLE12 cells were administered with scramble siRNA, Nrf2 siRNA, and compound $\mathrm{C}$ before treatment with Zingerone and
$\mathrm{H}_{2} \mathrm{O}_{2}$, after which the level of ROS and cellular injury were evaluated. MLE12 cells only treated with Zingerone $(50 \mu \mathrm{M})$ and $\mathrm{H}_{2} \mathrm{O}_{2}$ were used as the control group. AMPK or Nrf2 inhibition obviously augmented the ROS levels compared with the control group (Fig. 8a).

The results also demonstrated that compound $\mathrm{C}$ or Nrf2 siRNA significantly reversed the Zingerone-induced upregulation of the cellular viability rate, and the downregulation of LDH levels in MLE12 cells stimulated with $\mathrm{H}_{2} \mathrm{O}_{2}$ (Fig. 8b). The level of MDA or SOD activity of the compound C or Nrf2 siRNA group was significantly increased or decreased, respectively compared with the control group (Fig. 8c). In addition, the Zingerone-induced down regulation of TNF- $\alpha$ and IL-1 $\beta$ protein was attenuated in $\mathrm{H}_{2} \mathrm{O}_{2}$-stimulated MLE12 cells after compound C or Nrf2 siRNA administration (Fig. 8d).

\subsection{Inhibition of AMPK/Nrf2 blocks the protective role of Zingerone in asthmatic mice}

We speculated that the therapeutic effect of Zingerone on asthmatic mice was dependent on the activation of the AMPK/ Nrf2/HO-1 pathway. Therefore, in vivo experiments were performed to verify the above hypothesis. Mice were intraperitoneally injected with compound C or IT-delivered Nrf2 shRNA lentiviral vectors to block the AMPK/Nrf2 pathway. Treatment with compound $\mathrm{C}$ or the Nrf2 shRNAs lentiviral vector reversed the Zingerone-induced upregulation of SOD activity, GSH, CAT levels and down-regulated MDA levels compared with the (a)
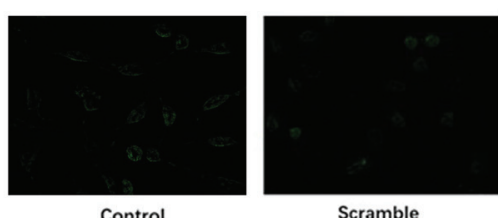

(c)

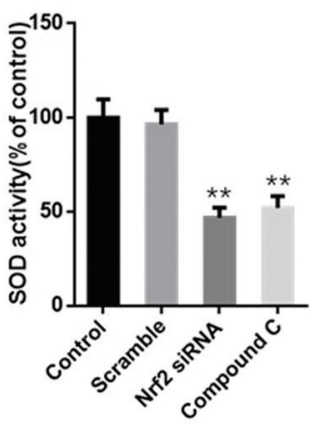

(b)
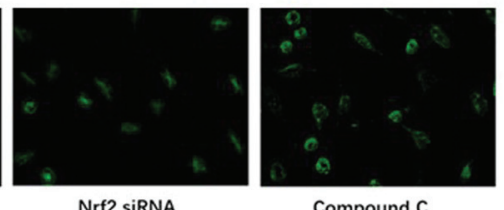

(d)

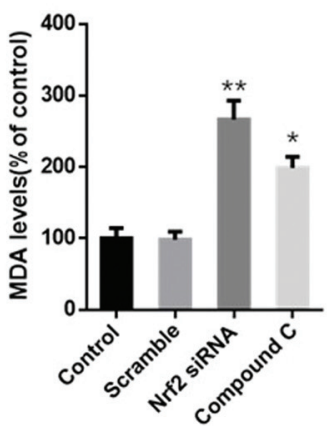

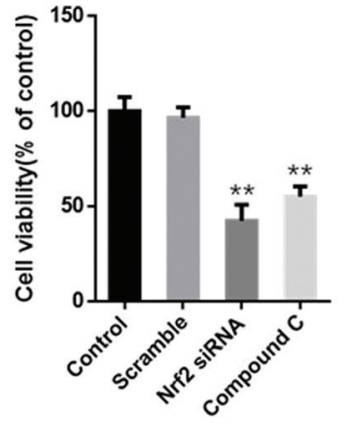
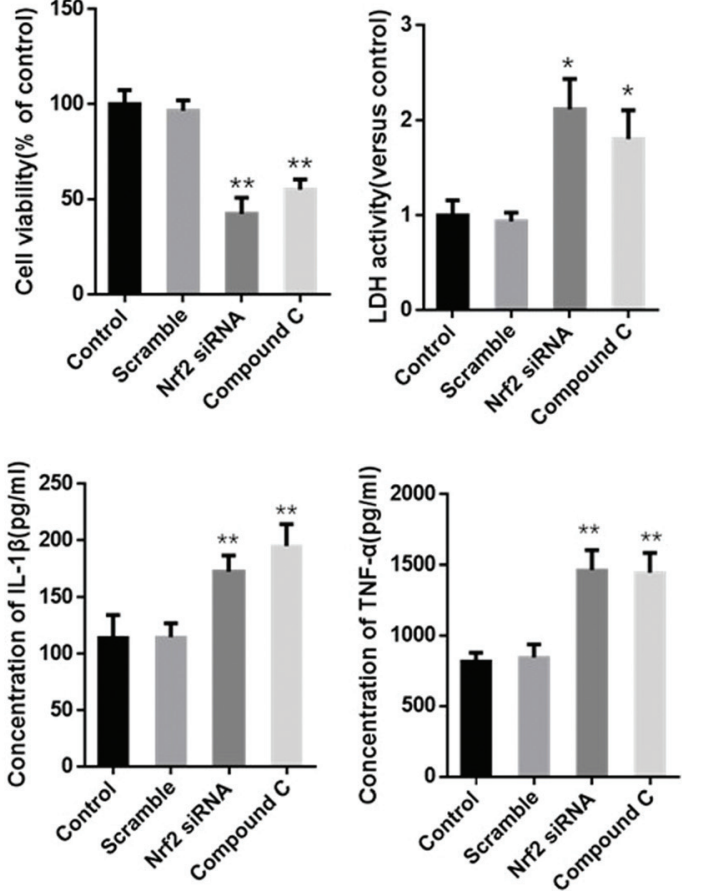

Fig. 8 Inhibition of AMPK/Nrf2 blocked the protective role of Zingerone in MLE12 cells. MLE12 cells only treated with $\mathrm{ZIN}$ and $\mathrm{H}_{2} \mathrm{O}_{2}$ were set as the control group. $(\mathrm{a}-\mathrm{c})$ Treatment with compound $\mathrm{C}$ or Nrf2 siRNA reversed the ZIN-induced upregulation of the cellular viability rate and SOD activity, as well as the downregulation of ROS and MDA levels. (d) The levels of TNF- $\alpha$ and IL-1 $\beta$ protein in the cell culture medium were upregulated by Compound $\mathrm{C}$ and Nrf2 siRNA compared with the control group. ${ }^{*} P<0.05$ versus control group; ${ }^{* \star} P<0.01$ versus control group. The data for each group were generated from three independent assays. 
(a)

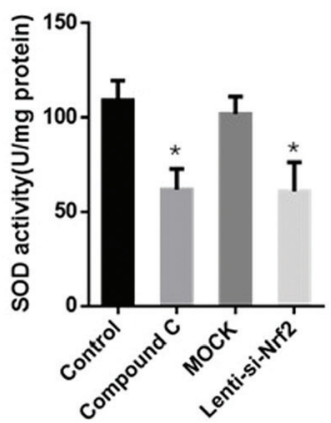

(b)

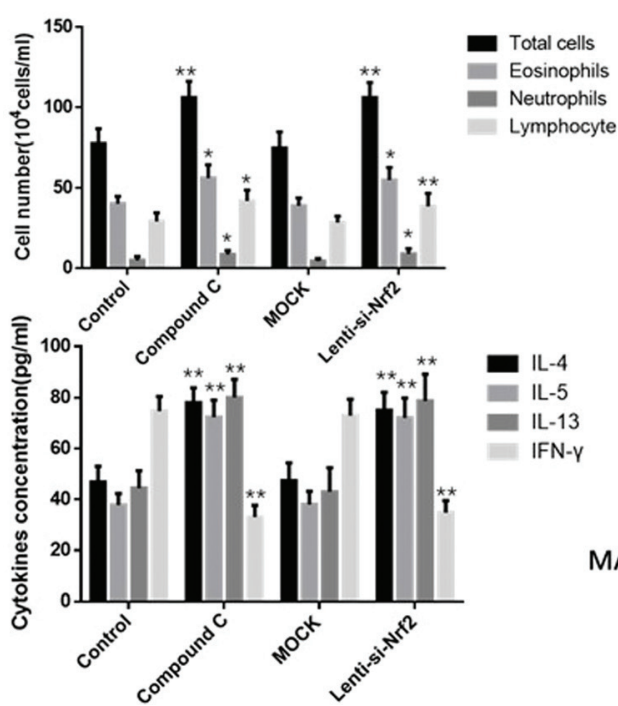

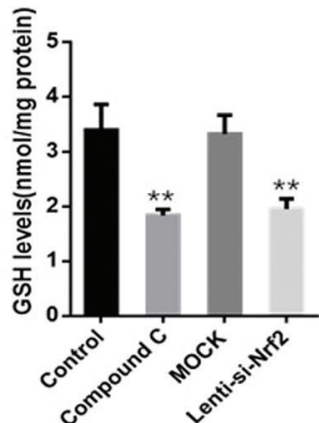

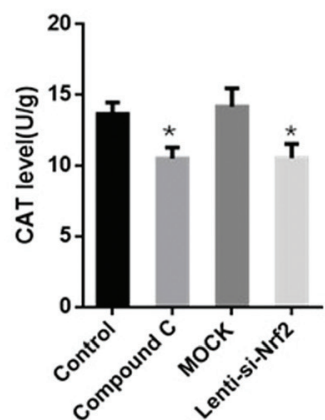

(c)

HE

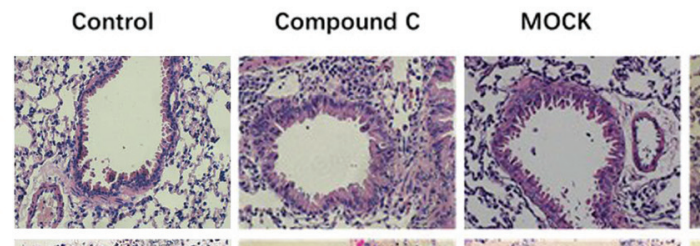

Lenti-si-Nrf2

PAS

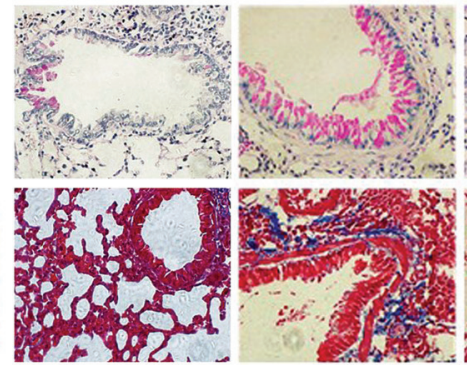

MASSON

Fig. 9 Inhibition of AMPK/Nrf2 blocked the protective role of Zingerone in asthmatic mice. Mice treated only with ZIN and OVA were set as the control group. (a) In the in vivo experiments, treatment with compound $\mathrm{C}$ or the Nrf2 shRNAs lentiviral vector reversed the ZIN-induced upregulation of SOD activity, GSH, and CAT levels, as well as the down-regulation of MDA levels compared with the control group. (b) Treatment with compound C or Nrf2 shRNA lentiviral vector increased the level of differential cells and cytokines in the BALF compared with the control group. (e) HE, PAS, and Masson staining showed that treatment with compound C or the Nrf2 shRNAs lentiviral vector remarkably attenuated the protective effect of ZIN on the airway inflammation of asthmatic mice. ${ }^{*} P<0.05$ versus control group; ${ }^{*} P<0.01$ versus control group. The data for each group were generated from three independent assays.

control group (mice only treated with Zingerone and OVA) (Fig. 9a). Moreover, treatment with compound $\mathrm{C}$ or the Nrf2 shRNAs lentiviral vector increased the level of differential cells and cytokines in the BALF compared with the control group (Fig. 9b). HE, PAS, and Masson staining also showed that treatment with compound $\mathrm{C}$ or the Nrf2 shRNAs lentiviral vector remarkably attenuated protective effect of Zingerone on the airways of asthmatic mice (Fig. 9c). The results demonstrated that treatment with compound $\mathrm{C}$ or the Nrf2 lentivirus reversed the protective effect of Zingerone in the asthmatic mice.

\section{Discussion}

To the best of our knowledge, this is the first report showing the effect of Zingerone in a mouse model of asthma. We showed that treatment with Zingerone was protective against OVAinduced asthma by regulating the AMPK/Nrf2/HO-1 pathway.

In the present study, we utilized MLE12 cells and the murine asthma model to explore the potential effect of
Zingerone on allergic airway inflammation. We demonstrated that Zingerone could reduce the level of ROS in the MLE12 cell $\mathrm{H}_{2} \mathrm{O}_{2}$ model, as well as diminish the cell damage induced by $\mathrm{H}_{2} \mathrm{O}_{2}$. Furthermore, the major enzymatic antioxidants in the lung consist of SOD, CAT, and GSH. ${ }^{25}$ The administration of Zingerone could upregulate SOD activity, CAT, and GSH levels, as well as downregulate the level of MDA in MLE12 cells or in the lung tissue of asthmatic rats. These findings suggest that Zingerone could alleviate $O S$ in an asthmatic model and protect MLE-12 cells from OS-induced cellular injury.

Multiple studies have demonstrated that NF-KB is a "central switch" involved in regulating the expression of over 300 genes that participate in the inflammatory response, immune response, regulation of apoptosis, and OS response. ${ }^{26-28}$ And there are five known NF-kB family members, RelA (p65), RelB, c-Rel, p50/p105 (NF-kB1), and p52/p100 (NF-kB2). ${ }^{29}$ In the present study, Zingerone clearly decreased the expression of p65(nucleus) and p-IкB in MLE12 cells stimulated with $\mathrm{H}_{2} \mathrm{O}_{2}$ or OVA-induced asthmatic mice. In addition, pathological immunohistochemical staining revealed that Zingerone 
reduced the expression of p65 around the small airways in the OVA-induced asthma model. We also found that Zingerone significantly decreased the synthesis and release of TNF- $\alpha$ and $\mathrm{IL}-1 \beta$ in an in vitro MLE12 cell $\mathrm{H}_{2} \mathrm{O}_{2}$ model and an in vivo model of rat asthma.

In this study, we demonstrated that Zingerone treatment prominently decreased inflammatory cell infiltration around the airways and goblet cell hyperplasia in OVA-challenged mice as shown by the HE and PAS staining. These results clearly confirm that Zingerone alleviates airway inflammation in vivo.

The precise mechanism by which the anti-inflammatory and antioxidant activity of Zingerone remains poorly understood. We hypothesized that Zingerone could relieve OVAinduced asthma by activating AMPK/Nrf2/HO-1 signaling pathway. Therefore, this study further detected whether Zingerone could activate AMPK to stimulate the Nrf2/HO-1 signaling pathway. These results demonstrate that Zingerone promoted AMPK phosphorylation, Nrf2 and HO-1 expression in the MLE12 cells and lung tissue of asthmatic rats. Under physiological conditions, Nrf2 translation is suppressed, whereas exposure to oxidative stress increases Nrf2 IRES-mediated expression. ${ }^{30}$ The induction of $\mathrm{HO}-1$ in endothelial cells exposed to oxidative stress are accompanied by the induction of protective enzymes. ${ }^{31}$ Moreover, pathological immunohistochemistry staining showed that increased levels of Nrf-2 and HO-1 were more expressed around the airway of the Zingerone treatment group compared to that of the OVA group.

To confirm the relationship of AMPK and Nrf2, pretreatment with compound C (AMPK inhibitor) attenuated the cellular protective, antioxidative, and anti-inflammatory properties of Zingerone and Nrf2 expression in MLE12 cells. In addition, treatment with compound $\mathrm{C}$ inhibited the promotive effect of Zingerone on Nrf2 protein expression in the lung tissues of asthmatic rats, suppressed the antioxidative stress and inflammatory activities of Zingerone, and aggravated OVA-induced airway inflammation.

AHR and eosinophilic airway inflammation are the two main features of asthma. AHR reflects increased/dysfunctional airway smooth muscle (ASM) contraction due to both direct or indirect stimuli. Our data demonstrates that Zingerone effectively reduces OVA-induced AHR in response to inhaled methacholine. Previous studies have shown that BALF eosinophilia represents a robust marker of T2-mediated disease, and can be reliably reproduced in the short term. In addition, the cytokines IL-4, IL-5, and IL-13 have been shown to play a critical role at several stages of eosinophil development and function. ${ }^{32-35}$ We found that Zingerone treatment could reduce the production of eosinophils and the release of IL-4, IL-5, and IL-13 in the alveolar lavage fluid supernatants of asthma models.

In conclusion, our study demonstrates that Zingerone ameliorates the release of inflammatory cytokines, AHR, and protects the airways from OS-induced injury in asthma by suppressing NF- $\mathrm{KB}$ and activating the Nrf2/HO-1 signaling pathways via $\mathrm{AMPK}$, which may lead to new strategies for the treatment of asthma.

\section{Conflicts of interest}

There are no conflicts to declare.

\section{Acknowledgements}

This work was supported by Jilin Provincial Department of Science and Technology (20180520130JH and 20190201005JC), Jilin Provincial Department of Finance (JLSCZD2019-019), National Science and Technology Major Special Project, institute of Pathogenic Biology, Chinese Academy of Medical Sciences (2017ZX10103004) and Research on the prevention and control of major chronic non-communicable diseases (2016YFC1304500).

\section{References}

1 Expert Panel Report 3 (EPR-3): Guidelines for the Diagnosis and Management of Asthma-Summary Report 2007, J. Allergy Clin. Immunol., 2007, 120, S94-S138. .

2 J. Bousquet, E. Mantzouranis, A. A. Cruz, N. Ait-Khaled, C. E. Baena-Cagnani, E. R. Bleecker, et al., Uniform definition of asthma severity, control, and exacerbations: document presented for the World Health Organization Consultation on Severe Asthma, J. Allergy Clin. Immunol., 2010, 126, 926-938.

3 R. J. Russell and C. Brightling, Pathogenesis of asthma: implications for precision medicine, Clin. Sci., 2017, 131, 1723-1735.

4 B. Spellberg and J. E. Edwards Jr., Type 1/Type 2 immunity in infectious diseases, Clin. Infect. Dis., 2001, 32, 76102.

5 J. V. Fahy, Type 2 inflammation in asthma-present in most, absent in many, Nat. Rev. Immunol., 2015, 15, 57-65.

6 A. Rahal, A. Kumar, V. Singh, B. Yadav, R. Tiwari, S. Chakraborty, et al., Oxidative stress, prooxidants, and antioxidants: the interplay, BioMed Res. Int., 2014, 2014, 761264.

7 A. A. da Cunha, N. K. Nunez, R. G. de Souza, M. H. Vargas, J. S. Silveira, G. L. Antunes, et al., Recombinant human deoxyribonuclease attenuates oxidative stress in a model of eosinophilic pulmonary response in mice, Mol. Cell. Biochem., 2016, 413, 47-55.

8 T. Nguyen, P. Nioi and C. B. Pickett, The Nrf2-antioxidant response element signaling pathway and its activation by oxidative stress, J. Biol. Chem., 2009, 284, 13291-13295.

9 H. M. Hafez, M. A. Ibrahim, M. Z. Zedan, M. Hassan and H. Hassanein, Nephroprotective effect of cilostazol and verapamil against thioacetamide-induced toxicity in rats may involve Nrf2/HO-1/NQO-1 signaling pathway, Toxicol. Mech. Methods, 2019, 29, 146-152.

10 L. E. Fredenburgh, M. A. Perrella and S. A. Mitsialis, The role of heme oxygenase- 1 in pulmonary disease, Am. J. Respir. Cell Mol. Biol., 2007, 36, 158-165. 
11 K. Mishina, M. Shinkai, T. Shimokawaji, A. Nagashima, Y. Hashimoto, Y. Inoue, et al., HO-1 inhibits IL-13-induced goblet cell hyperplasia associated with CLCA1 suppression in normal human bronchial epithelial cells, Int. Immunopharmacol., 2015, 29, 448-453.

12 M. C. Towler and D. G. Hardie, AMP-activated protein kinase in metabolic control and insulin signaling, Circ. Res., 2007, 100, 328-341.

13 C. Mo, L. Wang, J. Zhang, S. Numazawa, H. Tang, X. Tang, et al., The crosstalk between Nrf2 and AMPK signal pathways is important for the anti-inflammatory effect of berberine in LPS-stimulated macrophages and endotoxinshocked mice, Antioxid. Redox Signaling, 2014, 20, 574-588.

14 (GINA) GIfA, Global strategy for asthma management and prevention, 2016, GINA website http:/ginasthmaorg, 2019.

15 B. Ahmad, M. U. Rehman, I. Amin, M. U. R. Mir, S. B. Ahmad, A. Farooq, et al., Zingerone (4-(4-hydroxy-3methylphenyl) butan-2-one) protects against alloxaninduced diabetes via alleviation of oxidative stress and inflammation: Probable role of NF-kB activation, Saudi Pharm. J., 2018, 26, 1137-1145.

16 C. Liu, Q. Q. Wu, Z. L. Cai, S. Y. Xie, M. X. Duan, Q. W. Xie, et al., Zingerone attenuates aortic banding-induced cardiac remodelling via activating the eNOS/Nrf2 pathway, J. Cell. Mol. Med., 2019, 23, 6466-6478.

17 H. E. Mohamed and M. M. M. Badawy, Modulatory effect of zingerone against cisplatin or $\gamma$-irradiation induced hepatotoxicity by molecular targeting regulation, Appl. Radiat. Isot., 2019, 154, 108891.

18 T. Alibakhshi, M. J. Khodayar, L. Khorsandi, M. Rashno and L. Zeidooni, Protective effects of zingerone on oxidative stress and inflammation in cisplatin-induced rat nephrotoxicity, Biomed. Pharmacother., 2018, 105, 225-232.

19 C. H. Lee, D. H. Lee, S. M. Lee and A. S. Y. Kim, Otoprotective Effects of Zingerone on Cisplatin-Induced Ototoxicity, Int. J. Mol. Sci., 2020, 21, 3503-3514.

20 C. C. Lee, H. Y. Huang and B. L. Chiang, Lentiviralmediated GATA-3 RNAi decreases allergic airway inflammation and hyperresponsiveness, Mol. Ther., 2008, 16, 6065.

21 L. Zhu, X. Chen, L. Chong, L. Kong, S. Wen, H. Zhang, et al., Adiponectin alleviates exacerbation of airway inflammation and oxidative stress in obesity-related asthma mice partly through AMPK signaling pathway, Int. Immunopharmacol., 2019, 67, 396-407.
22 W. MacNee, Oxidative stress and lung inflammation in airways disease, Eur. J. Pharmacol., 2001, 429, 195-207.

23 G. Folkerts, J. Kloek, R. B. Muijsers and F. P. Nijkamp, Reactive nitrogen and oxygen species in airway inflammation, Eur. J. Pharmacol., 2001, 429, 251-262.

24 J. M. Campos-Martin, G. Blanco-Brieva and J. L. Fierro, Hydrogen peroxide synthesis: an outlook beyond the anthraquinone process, Angew. Chem., Int. Ed., 2006, 45, 6962-6984.

25 I. Rahman, S. K. Biswas and A. Kode, Oxidant and antioxidant balance in the airways and airway diseases, Eur. J. Pharmacol., 2006, 533, 222-239.

26 J. Hiscott, H. Kwon and P. Genin, Hostile takeovers: viral appropriation of the NF-kappaB pathway, J. Clin. Invest., 2001, 107, 143-151.

27 E. Turillazzi, M. Neri, D. Cerretani, S. Cantatore, P. Frati, L. Moltoni, et al., Lipid peroxidation and apoptotic response in rat brain areas induced by long-term administration of nandrolone: the mutual crosstalk between ROS and NF-kB, J. Cell. Mol. Med., 2016, 20, 601-612.

28 P. A. Baeuerle and V. R. Baichwal, NF-kappa B as a frequent target for immunosuppressive and anti-inflammatory molecules, Adv. Immunol., 1997, 65, 111-137.

29 S. Ghosh, M. J. May and E. B. Kopp, NF-kappa B and Rel proteins: evolutionarily conserved mediators of immune responses, Annu. Rev. Immunol., 1998, 16, 225-260.

30 W. Li, N. Thakor, E. Y. Xu, Y. Huang, C. Chen, R. Yu, et al., An internal ribosomal entry site mediates redox-sensitive translation of Nrf2, Nucleic Acids Res., 2010, 38, 778-788.

31 H. T. Cheng, C. J. Yen, C. C. Chang, K. T. Huang, K. H. Chen, R. Y. Zhang, et al., Ferritin heavy chain mediates the protective effect of heme oxygenase-1 against oxidative stress, Biochim. Biophys. Acta, 2015, 1850, 2506-2517.

32 G. Woltmann, C. A. McNulty, G. Dewson, F. A. Symon and A. J. Wardlaw, Interleukin-13 induces PSGL-1/P-selectindependent adhesion of eosinophils, but not neutrophils, to human umbilical vein endothelial cells under flow, Blood, 2000, 95, 3146-3152.

33 L. George and C. E. Brightling, Eosinophilic airway inflammation: role in asthma and chronic obstructive pulmonary disease, Ther. Adv. Chronic Dis., 2016, 7, 34-51.

34 B. N. Lambrecht and H. Hammad, The immunology of asthma, Nat. Immunol., 2015, 16, 45-56.

35 K. D. Patel, Eosinophil tethering to interleukin-4-activated endothelial cells requires both P-selectin and vascular cell adhesion molecule-1, Blood, 1998, 92, 3904-3911. 